This item was submitted to Loughborough's Institutional Repository (https://dspace.lboro.ac.uk/) by the author and is made available under the following Creative Commons Licence conditions.

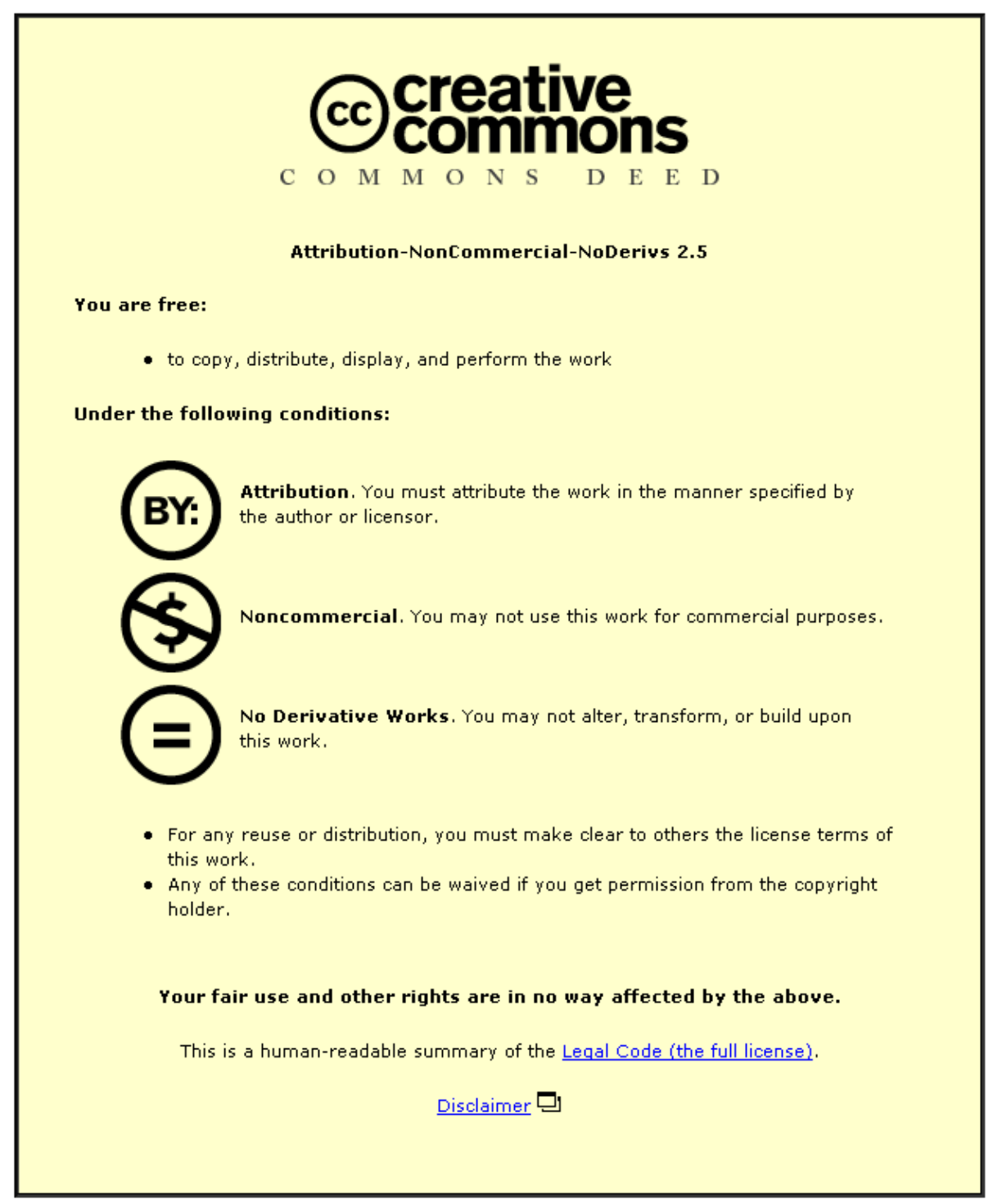

For the full text of this licence, please go to: http://creativecommons.org/licenses/by-nc-nd/2.5/ 


\title{
Technical appraisal of solar home systems in Bangladesh: a field investigation
}

\author{
Shahriar A. Chowdhury ${ }^{\mathrm{a}}$, Monjur Mourshed ${ }^{\mathrm{b}, *}$, S. M. Raiyan Kabir ${ }^{\mathrm{a}, \mathrm{d}}$, Moududul \\ Islam $^{\mathrm{a}}$, Tanvir Morshed ${ }^{\mathrm{b}}$, M. Rezwan Khan ${ }^{\mathrm{a}}$, Mohammad N. Patwary ${ }^{\mathrm{c}}$ \\ ${ }^{a}$ Department of Electrical and Electronic Engineering, United International University, Road 8A, \\ Dhanmondi, Dhaka 1209, Bangladesh \\ ${ }^{b}$ Department of Civil and Building Engineering, Loughborough University, Loughborough, \\ Leicestershire, LE11 3TU, United Kingdom \\ ${ }^{c}$ Department of Applied Technology, Staffordshire University, Beaconside, Stafford, Staffordshire, \\ ST18 OAD, United Kingdom \\ ${ }^{d}$ School of Engineering and Mathematical Sciences, City University London, Northampton Square, \\ London, ECIV OHB, United Kingdom
}

\begin{abstract}
Solar Home System (SHS) based rural electrification has experienced a considerable growth in Bangladesh since the start of the Rural Electrification and Renewable Energy Development Project (REREDP) in 2003. The initial target of 50,000 SHS installations in off-grid areas was achieved within 2.5 years, 3 years ahead of schedule. After achieving a revised target of 200,000 SHSs, ahead of schedule in early 2009, a new target of 1 million SHS installations by 2012 was set. The installation of about 0.5 million systems by March 2010 indicates that the current target may well be achieved before the deadline. The size of the SHS market and its impact on the regeneration of the rural economy makes it necessary to investigate the quality and reliability of the installed SHSs, if the continued success of the initiative is to be maintained. This paper reports on the findings from a field-based technical appraisal of SHS installations in Bangladesh. 60 geographically dispersed instal-
\end{abstract}

\footnotetext{
${ }^{*}$ Corresponding author

Email address: m.m.mourshed@lboro.ac.uk (Monjur Mourshed)
} 
lation sites were visited. Physical characteristics of the SHSs and their system components were tested to ascertain compliance with and deviations from the approved specifications. Despite the overwhelming success of the REREDP project, the study revealed various shortcomings. Notable among these are: incompatible and sub-optimal component configurations, faulty installations and a lack of effective quality assurance mechanism. The findings are contextualized and the ways to address the identified shortcomings are discussed.

Keywords: Solar home system (SHS), Technical appraisal, Bangladesh, Field investigation

\section{Symbols and abbreviations}

$\beta \quad$ Azimuth angle of the panel from the south

$\gamma \quad$ Inclination angle of the panel from horizontal

ADB Asian Development Bank

$C_{B} \quad$ Capacity of the battery

$C_{C} \quad$ Capacity of the charge controller

CFL Compact Fluorescent Lamp

$C_{P} \quad$ Capacity of the solar panel

$E_{B} \quad$ Energy flow to and from the charge controller to the battery

$E_{L} \quad$ Energy flow to the load from the charge controller

$E_{P} \quad$ Energy flow to the charge controller from the solar panel

GEF Global Environment Facility

GTZ Gesellschaft für Technische Zusammenarbeit

HVD High Voltage Disconnect

IDA International Development Association

IDB Islamic Development Bank 
IDCOL Infrastructure Development Company Limited

$I_{S C} \quad$ Short circuit current of the solar panel

KfW Kreditanstalt für Wiederaufbau

$L_{\text {rated }} \quad$ Connected load of the SHS

LVD Low Voltage Disconnect

NGO Non Government Organization

OEM Original Equipment Manufacturer

$P_{\text {self }} \quad$ Self power consumption of the charge controller

PO Partner Organization

$R_{C} \quad$ Contact resistance of the switch

$R_{C L} \quad$ Cable resistance from the charge controller to the load

REREDP Rural Electrification and Renewable Energy Development Project

$R_{P C} \quad$ Cable resistance from the panel to the charge controller

$S G \quad$ Specific gravity

SHS Solar Home System

$V_{H V D} \quad$ Voltage at high voltage disconnect

$V_{L V D} \quad$ Voltage at low voltage disconnect

$V_{O C} \quad$ Open circuit voltage of the solar panel

$V_{T} \quad$ Terminal voltage of the battery

\section{Introduction}

Solar home systems (SHSs) are widely accepted as a mature and effective means for off-grid electrification. About 0.5 million units have been installed in rural Bangladesh, enabling at least the same number of families to access a convenient source of energy $[1,2]$. These families had little or no prospect of gaining 
access to grid-connected electricity in a country where only $43 \%$ of the population is served by the grid [3]. Per capita electricity consumption in Bangladesh in 2007 was $143.6 \mathrm{kWh}$ [4], which was one of the lowest in the world.

Apart from the positive impacts of electrification at the grassroots level, SHS also puts Bangladesh on a safer trajectory with regard to energy security. More than $80 \%$ of the country's electricity generation is based on natural gas [5], which is not expected to last very long [6] unless new sources are discovered. The diversification of the energy infrastructure and the move away from fossil-fuels (through the increased use of renewable sources) have been cited as the key objective in the recently published policy by the Government [7]. Installations of very small scale renewable energy systems have, therefore, been encouraged both by the Government and non-government organizations. Further discussions on the progress and other issues pertinent to renewable energy in Bangladesh can be found in [8-11].

More than 86\% [12] of SHS installations in Bangladesh is carried out under the auspices of the publicly owned Infrastructure Development Company Limited (IDCOL) of Bangladesh, with grants and soft loans from donor agencies such as the International Development Association (IDA), Global Environment Facility (GEF), Asian Development Bank (ADB), Islamic Development Bank (IDB), Gesellschaft für Technische Zusammenarbeit (GTZ) and Kreditanstalt für Wiederaufbau (KfW). IDCOL's umbrella SHS project: Rural Electrification and Renewable Energy Development Project (REREDP) is implemented at the enduser level through various approved partner organizations (POs). The POs are responsible for the design, installation and after-sales service of the SHS, as well as for administering the micro-credit contracts with the endusers. The majority of the system components are sourced from local approved suppliers and original equipment manufacturers (OEM). The segregation of roles and responsibilities have encouraged the development of a local supply chain and worked well in the Bangladeshi context up to now. 
The market has grown steadily over the past years and has reached to a point where more robust regulatory and quality assurance frameworks are needed to safeguard endusers' investments and the sustainability of the initiative. It is, therefore, imperative that the updates to the existing policies, specifications and guidelines are based on an appraisal of the field performance of the SHSs.

SHSs discussed here are standalone solar power systems to provide electrical energy to households in off-grid rural areas. An SHS comprises a solar panel to convert sunlight into useful electrical energy, a battery as the energy storage medium to meet the demand during low/zero solar resource availability and a charge controller to regulate the charging and discharging of the battery. To enable deep discharge industrial-grade flooded-cell batteries are used as opposed to automotive-grade batteries. A typical solar home system is illustrated in Figure 1 . $E_{P}, E_{B}$, and $E_{L}$ are the energy output from the solar panel, energy to and from the battery and the energy to the load in $\mathrm{W}$, respectively.

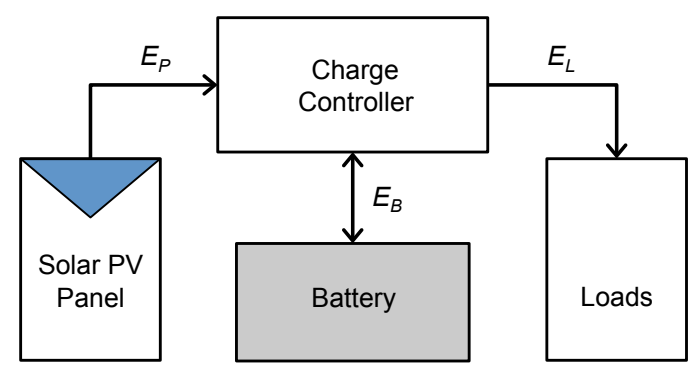

Figure 1: Components of a solar home system.

Realising the importance of the technical quality of the design, installation, operation and maintenance of the SHSs, a field-based technical appraisal of 60 geo- 
graphically dispersed installation sites (Figure 2) was carried out. Physical characteristics, as well as the factors associated with the operation and maintenance were observed to ascertain compliance with or deviations from the approved guidelines and specifications. This paper reports on findings from the field investigation and sheds light on ways to address the identified shortcomings in Bangladesh and in countries in similar circumstances.

The underlying methodology is presented in the next section, followed by a summary and an analysis of the findings. Recommendations for mitigating the shortcomings are discussed next with some thoughts on future directions.

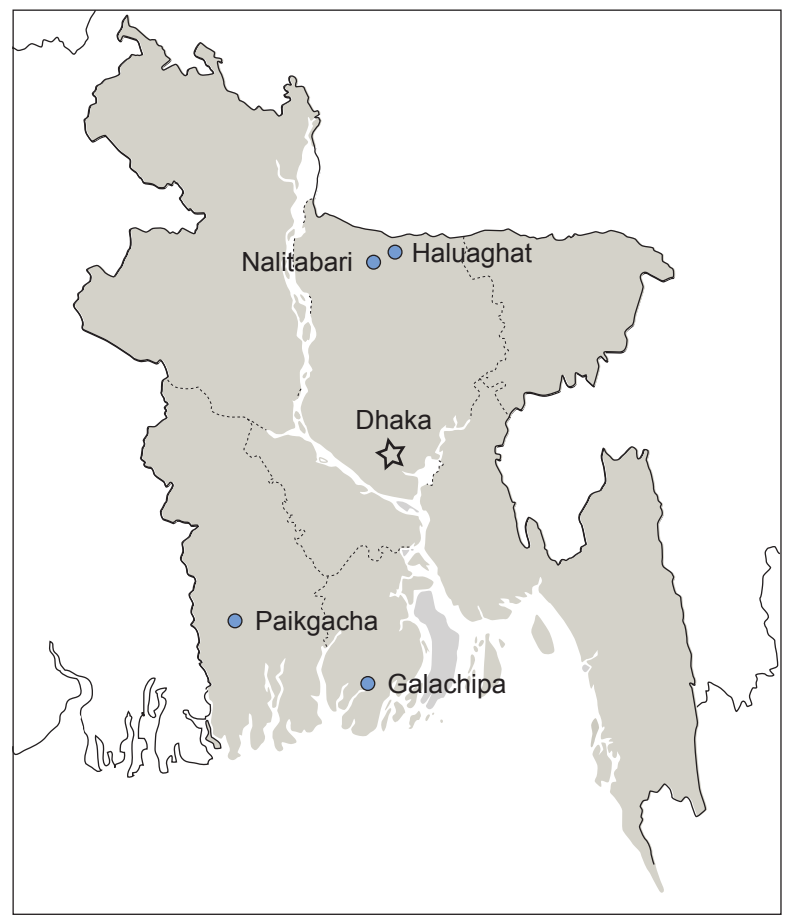

Figure 2: An outline map of Bangladesh with indicative locations of the four investigated sites. 


\section{Methodology}

Sixty standalone SHSs in four geographical locations in rural Bangladesh were visited between June 2008 and April 2009. The sites represented a variety of PV module types and system components, ages between 1 and 7 years and local microclimates from coastal to inland. The SHS sites were selected at random. The visit to every SHS site started with the collection of relevant information such as the age of installation and specifications of the system and its components. The data were obtained from the original agreement between the owner and the supplier or PO. Tests and observations carried out as part of the field investigation are summarized in Table 1 and described in the following sections.

\subsection{Solar panel}

At each site, observations were made to identify the positioning and orientation of the solar panels to ascertain if these are within the recommended guidelines. According to the approved specifications, the suggested values for azimuth $(\beta)$ and inclination $(\gamma)$ were $0^{\circ}$ from the south and $23^{\circ}$ from horizontal, respectively. Other physical characteristics such as the framing, junction box and support structure were observed. Distant observations were made in sites where climbing up to the roof was not practical for health and safety reasons. Observations were also made on the shading of the panels from trees and other obstructions. For each solar panel the short circuit current $\left(I_{S C}\right)$ and open circuit voltage $\left(V_{O C}\right)$ were measured to check if the panels were operating. Panel characterization in the field was not deemed to be practical due to the remoteness of some locations and resource constraints. 
Table 1: Field tests and observations

\begin{tabular}{|c|c|}
\hline Category & Tests and observations \\
\hline \multirow[t]{3}{*}{ Solar panel } & Orientation \\
\hline & Physical characteristics \\
\hline & Shading, dirt and maintenance \\
\hline \multirow[t]{3}{*}{ Battery } & Operating environment \\
\hline & Specific gravity \\
\hline & Nominal voltage \\
\hline Charge & Low voltage disconnect \\
\hline \multirow[t]{2}{*}{ controller } & High voltage disconnect \\
\hline & Indicator functioning \\
\hline \multirow[t]{2}{*}{ Wiring } & Continuity \\
\hline & Voltage drop \\
\hline \multirow[t]{2}{*}{ Switches } & Connectivity \\
\hline & Contact resistance \\
\hline Lamp-circuit & Startup time \\
\hline (inverter) & Black spots \\
\hline Connected & Type \\
\hline loads & Rated load \\
\hline Installation & Health and safety \\
\hline quality & Workmanship and maintenance \\
\hline
\end{tabular}




\subsection{Battery}

Specific gravity $(S G)$ of individual battery cells and the terminal voltage $\left(V_{T}\right)$ were measured. Visual observations were made on the operating environment, presence of sediments in the battery, level of electrolyte, sulfation, gassing, corrosion in connectors, terminal connection and cell color. In some cases sulfation, sediments and cell color could not be observed because of the opaque casing of the batteries. Visual observations were used as a proxy for the quality of the battery and its installation when other methods of obtaining relevant data were not deemed practical.

\subsection{Charge controller}

A variable DC power supply (a $24 \mathrm{~V}$ mobile unit with associated circuitry) was used to simulate both the solar panel and battery to test the charge controllers. All the SHS components were disconnected before testing. Low voltage disconnect $\left(V_{L V D}\right)$ and high voltage disconnect $\left(V_{H V D}\right)$ measurements were taken. Various indicators for load out, charging and battery charge status were checked for presence and accuracy. Operating environment, in particular the location of the charge controller was observed and noted.

\subsection{Wiring and switches}

For each connection to the load, the resistance $\left(R_{C L}\right)$ from the charge controller to the load was measured. Contact resistance $\left(R_{C}\right)$ was also measured for every switch. In cases where solar panels were accessible and weather was favourable, the resistance $\left(R_{P C}\right)$ from the panel to the charge controller was measured. Qualitative observations of the wiring and switches were made. 


\subsection{Lamp and lamp-circuit}

Each of the connected lamps was examined for startup time, black spots and illumination. In the case of systems shared with a neighbour, some of the lamps could not be examined due to the unavailability of the other party during the visit.

\subsection{Connected loads}

The type, number and rating of fixtures and equipments (loads) connected to the system were noted and the total load was calculated.

\subsection{Installation quality}

Qualitative assessments were carried out to identify health and safety risks and issues related to workmanship and maintenance. The observations assisted in drawing up a broader picture to understand the human and organizational factors in implementation.

\section{Findings}

Findings from the field investigation are discussed in the following sections. Descriptive statistics on various aspects of the field investigation are given in Table 2 and 3. Aspects related to installation quality such as workmanship, maintenance and health and safety are discussed in the relevant sections.

\subsection{Solar panels}

\subsubsection{Orientation}

The orientation of the solar panel was found to be dependent on the surrogate structure on which the panel was installed. In most cases (96.67\%), building roofs were used as a surrogate and there appeared to have been little flexibility in achieving the optimal orientation as the steel-framed mounts could not be adjusted. Out 
of the 60 panels observed, $43(71.67 \%)$ were found to be positioned within the recommended guidelines for azimuth $\left(\beta=0^{\circ}\right)$ and inclination $\left(\gamma=23^{\circ}\right) ; 14$ panels $(23.33 \%)$ had an inclination angle $(\gamma)$ either more or less than the optimum ${ }^{1}$; and $2(3.33 \%)$ were found facing towards the west. The orientation of the remaining 1 panel $(1.67 \%)$ could not be observed because it was inaccessible. The orientation and shading of the solar panels with respect to the optimal are illustrated in Figure 3.

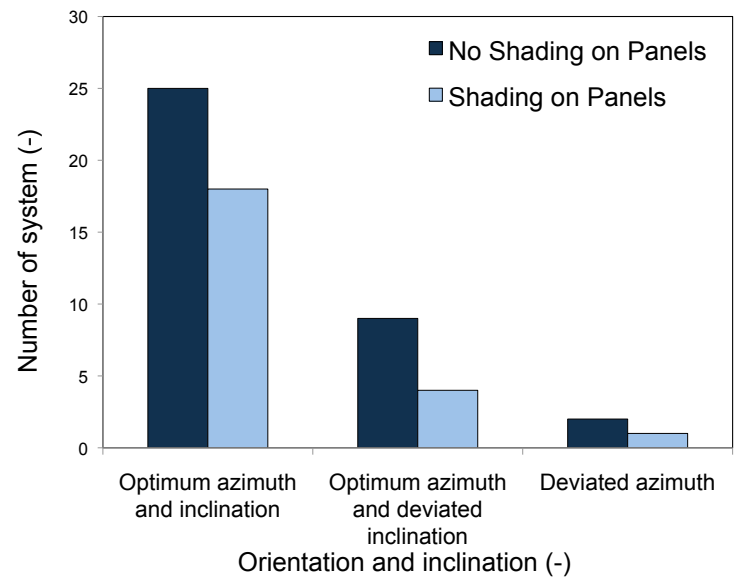

Figure 3: Orientation and shading of the solar panels with respect to the optimal $\beta$ and $\gamma$.

\subsubsection{Physical characteristics}

Nearly half of the panels were found to be placed directly on corrugated tin roofs that reduced ventilation underneath the panels. Such placements negatively impacted on the performance of the panels due to increased cell temperature. Two of the panels were found be placed on makeshift bamboo structures without ade-

\footnotetext{
${ }^{1}$ Of these 14 panels, 2 were placed horizontally on top of a flat roof.
} 
quate support to the ground, which was a health and safety risk to the occupants on the site. All the junction boxes were found to be encased but not necessarily air-tight, making them susceptible to corrosion. The observations of open circuit voltage $\left(V_{O C}\right)$ and short circuit current $\left(I_{S C}\right)$ of the panels indicated that they were operating. However, due to varying and overcast weather conditions, the measurements could not be relied upon for further reasoning. The average $V_{O C}$ was $18.01 \mathrm{~V}$ with a standard deviation of $3.66 \mathrm{~V}$. The mean for the $I_{S C}$ was $1.09 \mathrm{~A}$ with a standard deviation of $1.01 \mathrm{~A}$.

\subsubsection{Shading, dirt and maintenance}

Shading of the solar panels appeared to be commonplace among the investigated systems. $23(38.33 \%)$ out of the 60 investigated panels have been found to be shaded either in the morning or the evening and in some cases at both times. Shading from nearby evergreen trees (e.g. Mangifera indica) on the typical onestoried surrogate structure was found to be the primary reason. Majority of the panels were cleaned and maintained regularly, except in some cases where tree sap, bird droppings, dust, grime and mold were found on the panels.

\subsection{Battery}

A linear relationship can be deduced between the capacities of solar panels $\left(C_{P}\right)$ and batteries $\left(C_{B}\right)$ for different system configurations, illustrated in Table 4. However, some variations exist in the popular configurations of 40 and $50 \mathrm{Wp}$. For example, batteries of different capacities such as 55 (62.5\%), 60 (20.83\%), 71 $(12.5 \%)$ and $80 \mathrm{Ah}(4.2 \%)$ were used for $40 \mathrm{Wp}$ systems. Such variations can be said to be resulting in sub-optimal system configurations. 


\subsubsection{Terminal voltage}

The mean for the terminal voltage, $V_{T}$ of the observed batteries was $12.8 \mathrm{~V}$ with a standard deviation of $0.38 \mathrm{~V}$. The measurements were taken at different times of the day and at different charging conditions, which explain the deviations. All the batteries were industrial (deep-cycle) flooded lead-acid batteries; i.e. tubular positive plate batteries. The industrial batteries seem to be working well due to the fact that they can operate at a higher depth of discharge.

\subsubsection{Specific gravity}

The mean for the specific gravity, $S G$ of the observed batteries was $1209.68 \mathrm{~g} / \mathrm{L}$ with a standard deviation of $34.96 \mathrm{~g} / \mathrm{L}$. The reason for the deviation is similar to that of the deviation in the terminal voltages of the batteries. No significant difference in specific gravities in different cells of a battery was found.

\subsubsection{Operating environment}

In most of the cases the batteries were placed in dry and open places except one, which was found in a wet and moist area. With regard to air circulation in the operating environment, all but six were found in closed spaces where air circulation was hindered. This was potentially hazardous for the occupants due to the gas formed during overcharging.

The level of electrolyte, sedimentation, gassing, sulfation, corrosion in terminals and quality of terminal connections in all batteries were observed. In 12 (20\%) of the 60 batteries, water level was below the recommended level. 1 battery was found to be completely dry, whereas another one was found to be completely filled up with water (up to the vent plug). There appears to be a lack of effective training of endusers on the proper maintenance of the batteries. 


\subsection{Charge controller}

\subsubsection{Low and high voltage disconnect}

Charge controllers' low voltage disconnect, $\left(V_{L V D}\right)$ and high voltage disconnect, $\left(V_{H V D}\right)$ were measured to check compliance with the approved specifications $\left(V_{H V D}=14.3 \pm 0.2 \mathrm{~V}\right.$ and $\left.V_{L V D}=11.6 \pm 0.1 \mathrm{~V}\right)$ [13]. Measurements were taken with portable equipment consisting of a current controlled variable voltage source and a voltmeter. Out of the 60 charge controllers, $23(38.33 \%)$ were found with both the disconnect voltages within the specified limit and 20 (33.33\%) were found with both $V_{H V D}$ and $V_{L V D}$ outside the specified limit. 2 charge controllers' set points could not be measured as their disconnect points were varying.

The relatively older ( $>3$ years) charge controllers that were installed with the early SHS systems had the set points within the specified limit. In newer systems ( $<3$ years), the set points were found to be deviating from the specified limit. This is illustrated in Figure 4, where $V_{H V D}$ is plotted against $V_{L V D}$ along with the age of the system. The horizontal and vertical lines shows the ranges of allowable $V_{H V D}$ and $V_{L V D}$, respectively. One of the reasons for a low $V_{L V D}$ in some market leading systems is the vendor's intention to extend the duration of system operation during the night. This can be seen as a short-sighted marketing strategy, which diminishes battery life in the long run. Price for operating the battery at a lower depth of discharge is ultimately paid by the consumer with earlier than expected purchase of a replacement battery.

\subsubsection{Charging indicators}

The investigation also observed the operation of three indicators: battery charge status, load out and charging. 5 controllers were found without any battery status indicators, 5 more were found with this indicator malfunctioning and 2 more were found with malfunctioning charge status indicator. Although these indicators only 


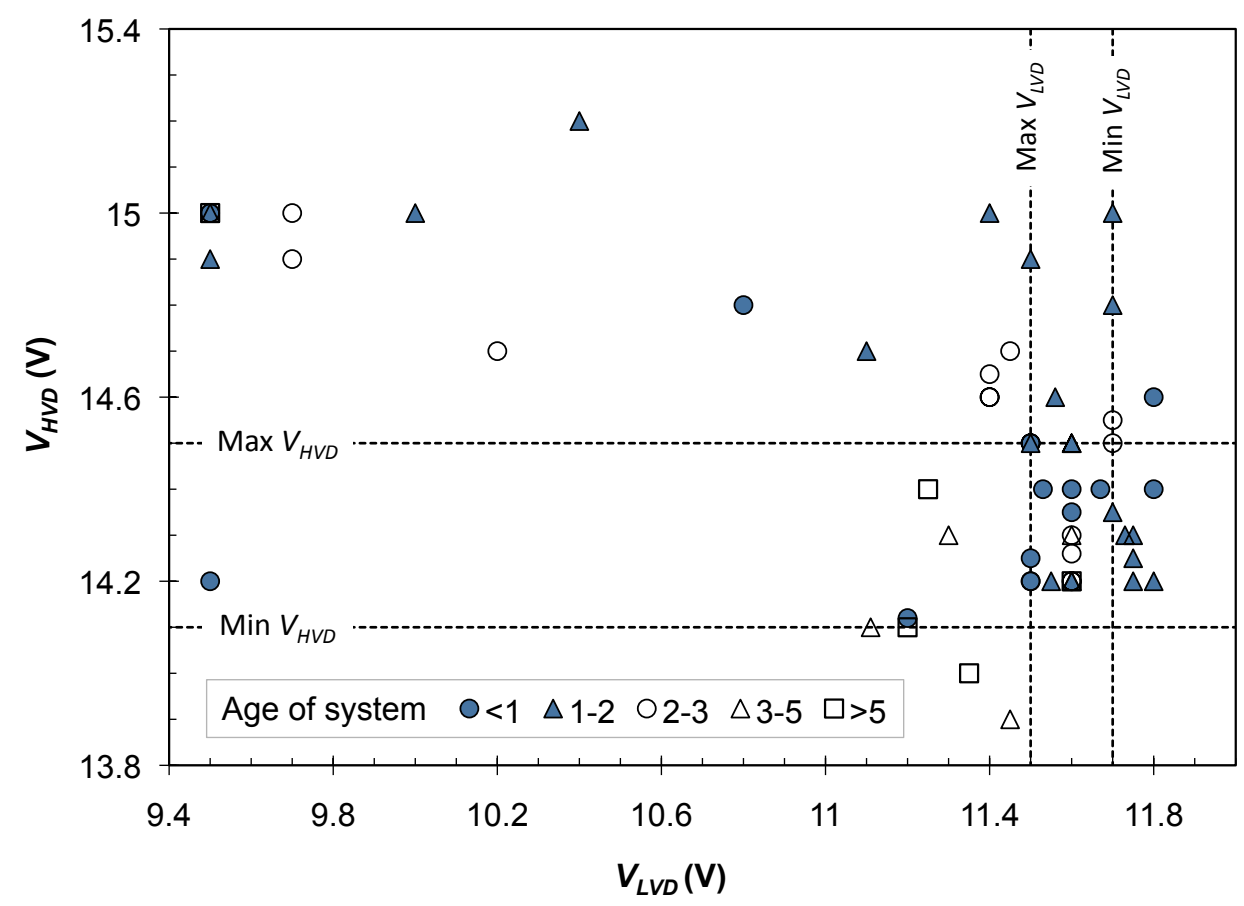

Figure 4: High voltage disconnect $\left(V_{H V D}\right)$ vs. low voltage disconnect $\left(V_{L V D}\right)$ of the 60 investigated charge controllers with respect to system age.

serve as a medium of communication with the user without necessarily indicating system malfunction, their importance in system operation and maintenance cannot be ignored.

\subsection{Lamps and lamp-circuit}

All the SHS investigated are found to be using fluoroscent lamps (mostly 10W), except in one case two $5 \mathrm{~W}$ CFLs were used to get the $10 \mathrm{~W}$ capacity. The illumination of all observed lamps was consistent with their rating in W. Delays in startup times were insignificant. However, more than half of the fluorescent lamps were found to be suffering from end-blackening problem. Lamp circuits have been found 
to be limiting power to the lamp to $6 \mathrm{~W}$. As a result all lamps were running with lower than the required power.

\subsection{Connected loads}

A large variation in the connected loads has been found for the 40 and $50 \mathrm{Wp}$ systems. The average for the connected load, $L_{\text {rated }}$ was $43.08 \mathrm{~W}$ with a standard deviation of $16.34 \mathrm{~W}$. The load varied between $16-60 \mathrm{~W}$ for the $40 \mathrm{Wp}$ and between 24-67 W for the $50 \mathrm{Wp}$ system, as shown in Table 5. It needs to be mentioned that the 40 and $50 \mathrm{Wp}$ systems collectively represents the majority (78\%) of the SHSs investigated in this study. Informal exploratory discussions with consumers revealed that in some cases they underestimated their demand for energy, which grew since the systems had been installed. The contrary has been found in cases where a higher capacity was installed to allow for future growth. The vendors have also been found to be selling overloaded packages to exaggerate the ability of the SHSs, only to meet consumer expectations and make a quick sale.

There was an indication that the affected consumers were not pleased about the under-performance of the overloaded systems even though they might have influenced the decisions on system sizes, initially or at the time of buying. The consumers also wished that the system specifications were more stringent so that the vendors did not have the flexibility to sell overloaded systems.

\subsection{Wiring and switches}

The resistance from the charge controller to the load, $\left(R_{C L}\right)$ was measured for 186 wires and cables in 60 sites. The average for $\left(R_{C L}\right)$ was $0.48 \Omega$ with a standard deviation of $0.94 \Omega$. The measurement was used to calculate the line voltage losses to ascertain compliance with the guideline (voltage loss $<3 \%$ in each subcircuit [13]). Only 58 (32\%) were found to be complying, where as $126(68 \%)$ 
were suffering from higher than specified cable voltage drop. A poor quality of workmanship was observed in the wiring installations, in particular in joints. The threshold for acceptable contact resistance $\left(R_{C}\right)$ of a switch was set at $0.3 \Omega .107$ (57\%) switches were found to be acceptable and the remaining 79 (43\%) were deemed to be unacceptable with higher than acceptable $R_{C}$. With regard to workmanship, 19 switches were found with loose connections. In all SHS installations AC switches have been used, which can be said to be responsible for high voltage

drop in contacts. It needs to be noted that current guidelines in Bangladesh do not specify the use of DC switches. The investigation also looked at the issues of salinity in coastal areas and its impact on $R_{C}$. No significant effect was observed.

\section{Recommendations and future directions}

Despite the headline grabbing success of SHS-based rural electrification in Bangladesh there is room for improvement, in particular during implementation at the grassroots level. This section contextualizes the findings from the field investigation and shares some thoughts on directions for remedial actions and future research.

\subsection{Regulatory framework and quality assurance}

It has been observed that the approved guidelines and specifications on SHS are too flexible to safeguard enduser interests in a developing market where consumer rights are barely protected. This is further complicated by the lack of endusers' understanding of the operation and maintenance of the system. Component manufacturers and suppliers, therefore, tend to focus on achieving the bare minimum, specified in the standards. The lack of an institutionalized quality assurance framework permit the supply chain to be disproportionately motivated by short-term commercial gains. An example of this is the variations in the disconnect voltages 
of the investigated charge controllers. In the relatively newer systems, the charge controllers' low voltage disconnect is often lower than the specified minimum, resulting in extended hours of system operation but at the cost of diminished battery life. Quality assurance of the supply chain, therefore, remains a challenge for the overall sustainability of the SHS-based electrification.

\subsection{System design and installation}

There is an abundance of sub-optimal SHS design and component configuration among the investigated systems. Sub-optimal conditions were found in the sizing of the PV panels, the operation of the charge controllers and the sizing of the batteries. One way to tackle this issue is to standardize the design of the SHSs that considers endusers' energy use profiles and the optimal configuration of the system components. With regard to site specific design parameters such as the siting and placement of panels and batteries, wiring and switching, there seems to be a shortage of skilled operatives in the field. Effective training and continuing professional development of field engineers and technicians may address some of these issues.

\subsection{Rating system for products and services}

Considering the increasing rate of penetration of SHSs in Bangladesh, there is a need to develop an easy-to-understand rating or labelling system for the products and services. This will benefit the endusers who may not possess the necessary technical know-how to make an informed decision for the purchase and maintenance of the SHS. The use of a rating system for all concerned supply chain stakeholders has the potential for improving the overall quality of installation and after sales service. 


\subsection{Approved technical specifications}

For IDCOL supported projects, the binding technical standard is the approved specification that has been a catalyst during the initial market penetration stages. Over the past decade, our understanding of the social aspects of technology adoption and implementation has improved. Advances in Light Emitting Diode (LED) technology and its applications in small scale home systems have changed the landscape for better. Approved specifications, therefore, need to be revised to incorporate new technological advances and to ensure optimal lifetime and operation of the SHS. The aspects requiring attention in the current technical specifications are:

- The self power consumption of the charge controllers can be reduced to enhance system performance. A mandatory cap on self power consumption can be specified to reduce the use of power hungry components.

- The quality of manufacturing in some of the locally sourced components need to be improved. For example, the specifications can mandate the use of printed circuit boards (PCB) with anti-corrosion coating as opposed to the wire connected circuit boards.

- Guidelines related to shading of PV panels and optimum positioning needs to account for the variations, typically found on site.

- Wiring sizes need to be specified in accordance with the connected loads for optimal system performance. The length of wiring need to be such that the rated voltage drop from the PV panel to the output is less than $3 \%$.

- To prevent corrosion, standaridized SHS switches need to be used with grounding of positive terminals of the charge controller along with the connection of switches with the negative line. 


\subsection{Training and monitoring}

Although English is the official second language in the country, there is a need for localized training materials, user guides and technical specifications to enable a wider stakeholder participation. Training and certification of design professionals and field operatives as well as their continuing professional development need further consideration.

\section{Conclusion}

This paper reported on a field-based technical appraisal of 60 standalone solar home systems in Bangladesh. The appraisal comprised testing and observation of SHS components for their sizing, placement and performance. Qualitative and quantitative assessments of the obtained data revealed various technical and organizational shortcomings, mostly during implementation at the grassroots level. With regard to the design of the installed SHSs notable factors were the over/under-sizing of system components and underperformance of the components with respect to the approved guideline and specifications. Placement of the key components such as solar panels and flooded-cell batteries were sub-optimal and in some cases posed health and safety risks to the endusers. At the top end of the organizational tree, the approved specifications and guidelines needed more frequent updates to keep up with the advances in technology and to incorporate research findings from Bangladesh and elsewhere. At the bottom end of the organizational tree, there is a need for further technical training of the field operatives. For effective maintenance and operation of the SHSs, the field offices need to be equipped with appropriate on-site and off-site testing facilities to enable them to make informed decisions.

No significant evidence of underperformance of the system components due 
to ageing was found. It should be noted that the project was only six years old. However, the quality of the components in recent installations worsened from the initial installations. The size of the market, combined with recent growth patterns, makes it imperative that the supply chain is more robustly regulated to protect endusers' rights and investments.

Findings of this research were presented to IDCOL and evidence suggest that these were taken on board. Punitive actions were taken against some of the suppliers for deviating from the approved specifications. An update to the technical specifications and guidelines for SHS installations is currently underway. Enhanced training of all involved in the field implementation is also under active consideration.

\section{References}

[1] IDCOL, Renewable energy projects: Idcol solar energy program, Dhaka, Bangladesh (March 2010).

[2] REEIN, Solar PV Electrification Program in Bangladesh, Renewable Energy and Environmental Information Network, Dhaka, Bangladesh, 2010.

[3] MPEMR, 3-Year Road Map for Power Sector Reform (2008-2010), Ministry of Power, Energy and Mineral Resources, Dhaka, Bangladesh, 2008.

[4] IEA, Energy Balances of Non-OECD Countries, International Energy Agency, Paris, France, 2009.

[5] BPDB, Annual Report 2007-2008, Bangladesh Power Development Board, Dhaka, Bangladesh, 2009.

[6] MPEMR, Power System Master Plan Update, Ministry of Power, Energy and Mineral Resource, Dhaka, Bangladesh, 2006. 
[7] MPEMR, Renewable Energy Policy of Bangladesh, Ministry of Power, Energy and Mineral Resource, Dhaka, Bangladesh, 2008.

[8] A. S. Islam, M. Islam, T. Rahman, Effective renewable energy activities in bangladesh, Renewable Energy 31 (5) (2006) 677-688.

[9] S. N. Uddin, R. Taplin, A sustainable energy future in bangladesh: Current situation and need for effective strategies, in: Proceedings of the 2nd Joint International Conference on Sustainable Energy and Environment (SEE 2006), Bangkok, Thailand, 2006.

[10] M. R. Islam, M. R. Islam, M. R. A. Beg, Renewable energy resources and technologies practice in bangladesh, Renewable and Sustainable Energy Reviews 12 (2) (2008) 299-343.

[11] M. Sarkar, M. Ehsan, M. Islam, Issues relating to energy conservation and renewable energy in bangladesh, Energy for Sustainable Development 7 (2) (2003) 77-87.

[12] M. Z. Baten, E. M. Amin, A. Sharin, R. Islam, S. A. Chowdhury, Renewable energy scenario of bangladesh: Physical perspective, in: Proceedings of the 1st International Conference on the Developments in Renewable Energy Technology, United International University, Dhaka, Bangladesh, 2009, pp. $225-229$.

[13] IDCOL, Technical specifications for solar home systems (shs), rural electrification and renewable energy development (pv component) project (reredp) (January 2005). 
Table 2: Descriptive statistics on system information, solar panel and battery.

\begin{tabular}{|c|c|c|c|c|c|}
\hline Variable & Scale & $\mathbf{N}$ & $\%$ & Mean & SD \\
\hline \multicolumn{6}{|c|}{ System information } \\
\hline \multirow[t]{4}{*}{$A(\mathrm{yr})$} & $0-1$ & 14 & 23.33 & & \\
\hline & $1-3$ & 35 & 58.33 & & \\
\hline & $3-5$ & 7 & 11.67 & & \\
\hline & $5+$ & 4 & 6.67 & & \\
\hline \multicolumn{6}{|c|}{ Solar panel } \\
\hline \multirow[t]{7}{*}{$C_{P}(\mathrm{Wp})$} & 21 & 1 & 1.67 & & \\
\hline & 30 & 2 & 3.33 & & \\
\hline & 40 & 24 & 40.00 & & \\
\hline & 50 & 22 & 36.67 & & \\
\hline & 60 & 2 & 3.33 & & \\
\hline & 65 & 7 & 11.67 & & \\
\hline & 85 & 1 & 1.67 & & \\
\hline$V_{O C}(\mathrm{~V})$ & & & & 18.01 & 3.66 \\
\hline$I_{S C}(\mathrm{~A})$ & & & & 1.09 & 1.01 \\
\hline \multicolumn{6}{|l|}{ Battery } \\
\hline \multirow[t]{8}{*}{$C_{B}(\mathrm{Ah})$} & 30 & 1 & 1.67 & & \\
\hline & 47 & 3 & 5.00 & & \\
\hline & 55 & 15 & 25.00 & & \\
\hline & 60 & 5 & 8.33 & & \\
\hline & 71 & & 35.00 & & \\
\hline & 80 & 21 & 35.00 & & \\
\hline & 100 & 11 & 18.33 & & \\
\hline & 130 & 1 & 1.67 & & \\
\hline
\end{tabular}


Table 3: Descriptive statistics on charge controller, wiring, switches and connected loads.

\begin{tabular}{|c|c|c|c|c|c|}
\hline Variable & Scale & $\mathbf{N}$ & $\%$ & Mean & SD \\
\hline \multicolumn{6}{|c|}{ Charge controller } \\
\hline \multirow[t]{3}{*}{$C_{C}(\mathrm{~A})$} & 5 & 6 & 10.00 & & \\
\hline & 6 & 4 & 6.67 & & \\
\hline & 10 & 50 & 83.33 & & \\
\hline$V_{L V D}(\mathrm{~V})$ & & & & 11.21 & 0.82 \\
\hline$V_{H V D}(\mathrm{~V})$ & & & & 14.54 & 0.61 \\
\hline$P_{\text {self }}(\mathrm{W})$ & & & & 0.31 & 0.17 \\
\hline \multicolumn{6}{|c|}{ Wiring and switches } \\
\hline$R_{P C}(\Omega)$ & & 60 & & 0.64 & 1.40 \\
\hline$R_{C L}(\Omega)$ & & 186 & & 0.48 & 0.39 \\
\hline$R_{C}(\Omega)$ & & 186 & & 1.10 & 0.94 \\
\hline \multicolumn{6}{|c|}{ Connected load } \\
\hline \multirow[t]{8}{*}{$L_{\text {rated }}(\mathrm{W})$} & $0-10$ & 0 & 0.00 & & \\
\hline & $11-20$ & 7 & 11.67 & & \\
\hline & $21-30$ & 8 & 13.33 & & \\
\hline & $31-40$ & 11 & 18.33 & & \\
\hline & $41-50$ & 9 & 15.00 & & \\
\hline & $51-60$ & 19 & 31.67 & & \\
\hline & $61-70$ & 5 & 8.33 & & \\
\hline & $71-80$ & 24 & 1.67 & & \\
\hline
\end{tabular}


Table 4: Number of systems $(N=60)$ with different battery and panel capacities.

\begin{tabular}{lcccccccc}
\hline & \multicolumn{7}{c}{ Panel capacity (Wp) } & \\
\cline { 2 - 7 }$C_{B}(\mathrm{Ah})$ & $\mathbf{2 1}$ & $\mathbf{3 0}$ & $\mathbf{4 0}$ & $\mathbf{5 0}$ & $\mathbf{6 0}$ & $\mathbf{6 5}$ & $\mathbf{8 5}$ & Total \\
\hline 30 & 1 & - & - & - & - & - & - & 1 \\
47 & - & 3 & - & - & - & - & - & 3 \\
55 & - & - & 15 & - & - & - & - & 15 \\
60 & - & - & 5 & - & - & - & - & 5 \\
71 & - & - & 3 & - & - & - & - & 3 \\
80 & - & - & 1 & 20 & - & - & - & 21 \\
100 & - & - & - & 2 & 2 & 7 & - & 11 \\
130 & - & - & - & - & - & - & 1 & 1 \\
Total & 1 & 3 & 24 & 22 & 2 & 7 & 1 & \\
\hline
\end{tabular}


Table 5: Number of systems $(N=60)$ with different load ranges and panel capacities.

\begin{tabular}{lcccccccc}
\hline & \multicolumn{7}{c}{ Panel capacity $(\mathrm{Wp})$} & \\
\cline { 2 - 6 }$L_{\text {rated }}(\mathrm{W})$ & $\mathbf{2 1}$ & $\mathbf{3 0}$ & $\mathbf{4 0}$ & $\mathbf{5 0}$ & $\mathbf{6 0}$ & $\mathbf{6 5}$ & $\mathbf{8 5}$ & Total \\
\hline $0-10$ & - & - & - & - & - & - & - & 0 \\
$11-20$ & 1 & 2 & 4 & - & - & - & - & 7 \\
$21-30$ & - & - & 6 & 2 & - & - & - & 8 \\
$31-40$ & - & - & 5 & 5 & - & 1 & - & 11 \\
$41-50$ & - & - & 2 & 6 & - & 1 & - & 9 \\
$51-60$ & - & - & 8 & 5 & 2 & 3 & 1 & 19 \\
$61-70$ & - & - & - & 4 & - & 1 & - & 5 \\
$71-80$ & - & - & - & - & - & 1 & - & 1 \\
Total & 1 & 2 & 25 & 22 & 2 & 7 & 1 & \\
\hline
\end{tabular}

